\title{
Primeiro transplante duplo de fígado esquerdo intervivos adultos do Brasil
}

\author{
The first dual left lobe adult-to-adult liver transplantation in Brazil
}

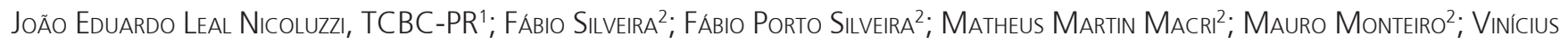
WOITOVICZ ; FÁBIO STALCHIMIDT ${ }^{2}$

\section{R E S U M O}

\begin{abstract}
O transplante hepático inter vivos adulto expandiu as possibilidades terapêuticas para pacientes com insuficiência hepática terminal. A necessidade de um volume hepático adequado que será retirado do doador e necessário ao receptor limita sua utilização em alguns casos. Apresentamos um caso em que se utilizou dois lobos esquerdos de dois doadores vivos no intuito de prover parênquima hepático suficiente ao receptor.
\end{abstract}

Descritores: Pacientes. Insuficiência hepática. Transplantes. Doadores vivos. Transplante de fígado.

\section{INTRODUÇÃO}

$\mathrm{O}$ transplante hepático utilizando doadores vivos (THV), pioneiramente realizado em 1988 por Raia', surgiu voltado para a população pediátrica sendo que o seu refinamento técnico acabou por sedimentá-lo como um valioso procedimento ${ }^{2}$ na redução da mortalidade em lista desses pacientes ${ }^{3}$. A escassez de órgãos impingiu a evolução da técnica para seu uso em pacientes adultos, inicialmente utilizando fígados esquerdos, mas em virtude da limitação de tamanho, foi expandido para fígados direitos $^{4}$.

O THV envolve questões técnicas e éticas que estão em contínuo debate e evolução. As vantagens do THV incluem um tempo de espera significativamente diminuído, planejamento da cirurgia (permitindo estabilização clínica do paciente) e uso de um enxerto de um doador saudável com mínimo tempo de isquemia 5 . As desvantagens incluem o recebimento de um enxerto de menor tamanho e uma potencial taxa de complicações cirúrgicas maior, tanto para o receptor quanto para o doador.

Atualmente o sistema brasileiro de alocação de fígado para transplante é determinado pelo modelo de doença hepática terminal (MELD), que é capaz de prever a sobrevida em três meses de pacientes com doença hepática terminal ${ }^{6}$, porém esse método possui conhecidas limitações, principalmente em pacientes com hemorragia digestiva, ascite refratária, hiponatremia e encefalopatia hepática ${ }^{7}$.

\section{QUADRO CLÍNICO}

O receptor em questão era do sexo masculino, 52 anos, portador de insuficiência hepática crônica terminal devido ao álcool, em abstinência e que apresentou em sua descompensação inicial episódio de hemorragia digestiva alta e encefalopatia hepática, com um MELD de 17. Sua evolução clínica resultou em melhora de seu escore MELD, que flutuava entre 9-12, porém com episódios recorrentes de encefalopatia, necessitando algumas vezes manejo em unidade de terapia intensiva. Em virtude de seu baixo MELD, e conseqüente baixa probabilidade de receber um órgão de doador cadáver, indicou-se THV. A avaliação de seus dois potenciais doadores (filho e sobrinha), respeitando as diretrizes já estabelecidass,9, está exposta na tabela 1.

Baseando-se na avaliação da volumetria pré-operatória foi contra-indicada a doação do fígado direito de ambos os potenciais doadores, em virtude dos seus baixos volumes residuais. Na inexistência de outros potenciais doadores, optou-se pela utilização dos dois fígados esquerdos de ambos os doadores, permitindo um volume de enxerto adequado para as necessidades do receptor e associado a seguros volumes remanescentes aos doadores.

\section{ASPECTOS TÉCNICOS}

O chamado transplante duplo de fígado esquerdo inter vivos adultos (DLLT) foi realizado pela primeira vez

Trabalho realizado no Hospital e Maternidade Angelina Caron e Instituto para Cuidado do Fígado - Curitiba - Paraná - Brasil

1. Chefe do Serviço de Transplantes do Hospital Angelina Caron- Curitiba -PR-BR; 2. Médicos do Serviço de Transplantes do Hospital Angelina Caron- Curitiba -PR-BR. 
Tabela 1 - Volumes estimados pela clínica e radiologia.

\begin{tabular}{|c|c|c|c|c|}
\hline Receptor & \multicolumn{2}{|l|}{ Doador 1} & \multicolumn{2}{|l|}{ Doador 2} \\
\hline Peso $(k g)$ & \multicolumn{2}{|l|}{ Peso $(\mathrm{kg})$} & \multicolumn{2}{|l|}{ Peso (kg) } \\
\hline 86 & \multicolumn{2}{|l|}{80} & \multicolumn{2}{|l|}{63} \\
\hline GRBW $^{1} \quad 0,8 \%$ & \multicolumn{2}{|c|}{ Volume estimado (clínica) ${ }^{2}$} & \multicolumn{2}{|c|}{ Volume estimado (clínica) ${ }^{2}$} \\
\hline 688 & \multicolumn{2}{|c|}{1600} & \multicolumn{2}{|c|}{1260} \\
\hline GRBW $^{1} 1 \%$ & Fígado direito & 960 & Fígado direito & 756 \\
\hline 860 & Fígado esquerdo & 640 & Fígado esquerdo & 504 \\
\hline GRBW $11,2 \%$ & \multicolumn{2}{|c|}{ Volume estimado (radiologia) } & \multicolumn{2}{|c|}{ Volume estimado (radiologia) } \\
\hline \multirow[t]{4}{*}{1032} & Fígado direito & 831,2 & Fígado direito & 822 \\
\hline & Fígado esquerdo & 433,1 & Fígado esquerdo & 428,1 \\
\hline & Seg. Lateral esquerdo & 93 & Seg. Lateral esquerdo & 135,1 \\
\hline & \multicolumn{2}{|c|}{$\begin{array}{l}\text { Volume remanescente ideal }{ }^{3} \\
>640\end{array}$} & \multicolumn{2}{|c|}{$\begin{array}{l}\text { Volume remanescente ideal }{ }^{3} \\
>504\end{array}$} \\
\hline
\end{tabular}

1- Graft size to body weight (GRBW): mínimo 0,8\%, ideal 1\%, ótimo 1,2\%.2 - Volume estimado clinicamente: 2\% do peso corpóreo (2-2,5\%), lado direito 60\%, lado esquerdo 40\%.3 - Volume remanescente ideal deve ser $>0.4 \%$ (massa hepática remanescente/pesox100\%), ie, 40\% volume do fígado.

no ano 2000, na Coréia do Sul ${ }^{10}$. Dentre suas variantes técnicas, utilizamos os segmentos hepáticos II-IV e incluindo a veia hepática média, conforme ilustrado na figura 1.

A anatomia arterial de ambos os doadores não apresentava dificuldades ao procedimento, sendo que o doador 1 apresentava a artéria hepática esquerda proveniente como tronco único da artéria gástrica esquerda. Em relação à anatomia da veia porta, ambos não possuíam variação anatômica. A avaliação da anatomia biliar foi realizada com colangiografia intra-operatória.

A hepatectomia do receptor foi realizada preservando-se a veia cava inferior e os óstios da veia hepática direita, média e esquerda, assim como os ramos direito e esquerdo da veia porta. A drenagem venosa dos enxertos foi realizada em tronco único reconstruído na cirurgia de mesa (veia hepática média e esquerda), sendo que o enxerto esquerdo foi implantado em tronco único da veia hepática média e esquerda do receptor, e o enxerto direito na veia hepática direita do receptor. A reconstrução portal foi realizada utilizando-se os respectivos ramos portais para o enxerto esquerdo e direito. Após essa etapa os enxertos foram reperfundidos, seguidos da reconstrução arterial. A reconstrução biliar foi realizada com uma colédoco-colédoco anastomose término-terminal para o enxerto direito e hepático-jejunoanastomose para o enxerto esquerdo (Figura 2).

Para evitar esgarçamento das anastomoses vasculares decorrentes do menor tamanho do enxerto esquerdo comparado à cavidade abdominal do receptor, um expansor tecidual foi posicionado no hipocôndrio direito (Figura 3).

A recuperação pós-operatória dos doadores ocorreu sem intercorrências, ambos receberam alta hospitalar no quinto dia de pós-operatório, não necessitando novos internamentos.

O receptor recebeu imunossupressão padrão (tacrolimus, micofenolato mofetil e prednisona) e necessitou três sessões de hemodiálise no pós-operatório (PO).

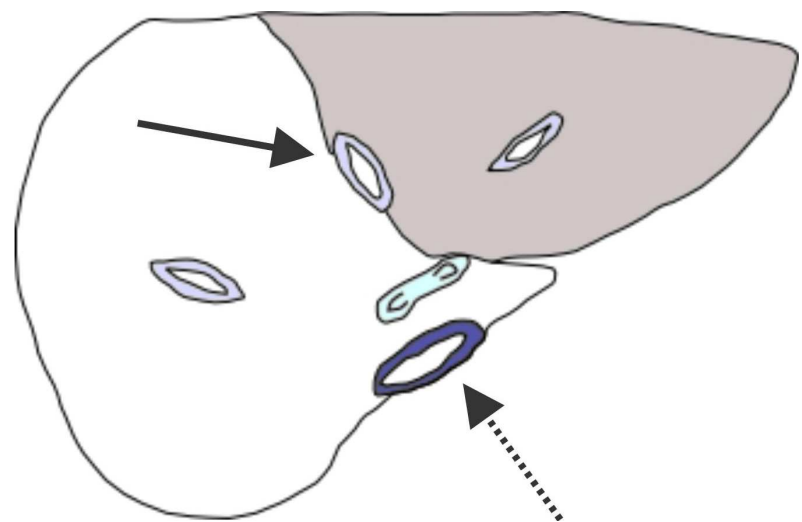

Figura 1 - Visão axial do enxerto (segmentos II,III e IV) com a veia hepática média. Seta = veia hepática média; seta pontilhada $=$ veia cava inferior .

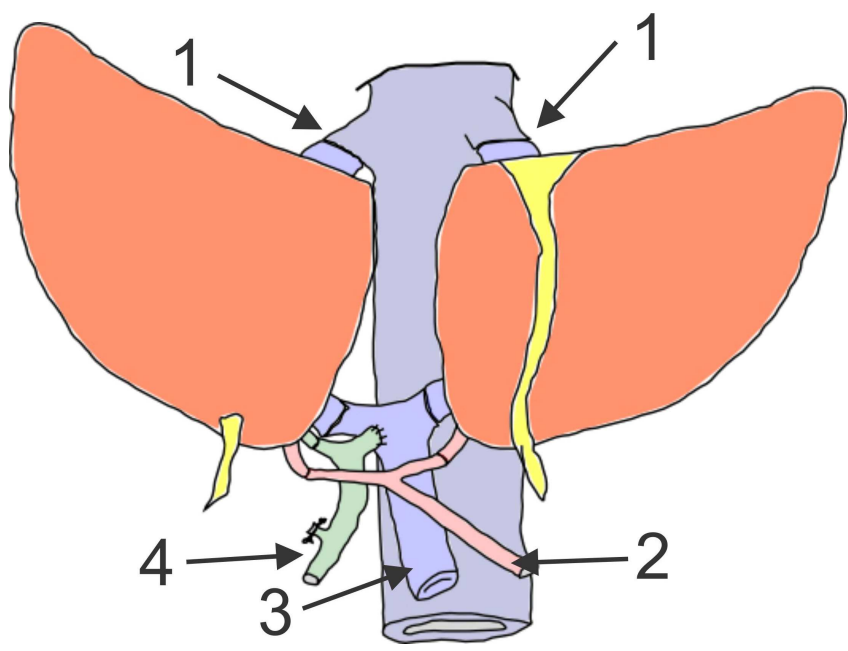

Figura 2 - Aspecto do posicionamento e anastomoses dos enxertos. 1 = anastomoses de drenagem da veia hepática média e esquerda com a veia cava inferior; $2=$ artéria hepática; $3=$ veia porta; $4=$ via biliar. $A$ hepatico-jejuno-anastomose com o enxerto esquerdo foi deliberadamente omitida para fins didáticos. 


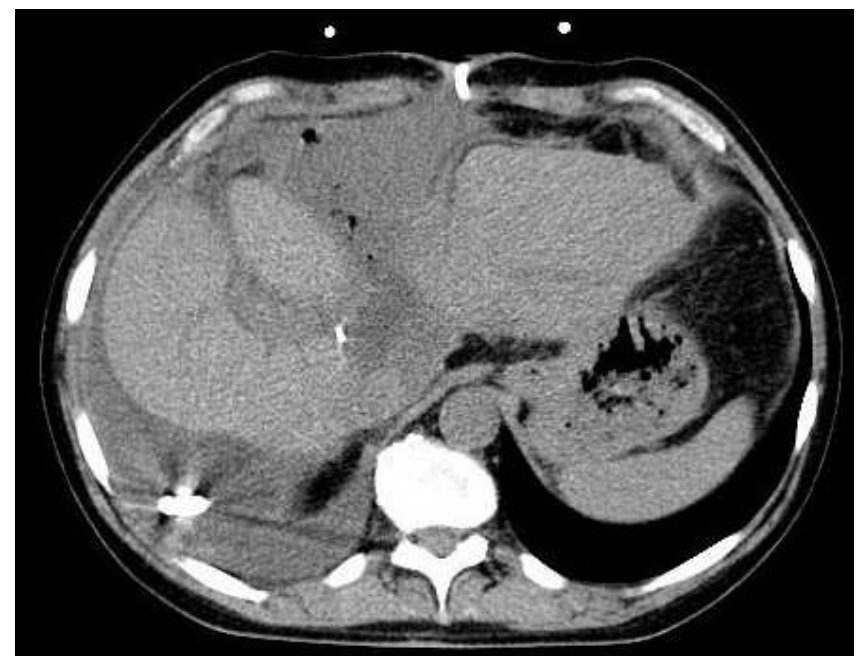

Figura 3 - Corte axial demonstrando os dois enxertos e o posicionamento do expansor tecidual no lado direito (2 semanas pós-transplante).

Apresentou alteração neurológica do tipo delirium no $11^{\circ} \mathrm{PO}$, sendo manejada com suporte hidro-eletrolítico e substituição do tacrolimus por ciclosporina. Apresentou complicação cirúrgica de fístula biliar da anastomose bíleo-digestiva, tratada com drenagem percutânea. Recebeu alta no $21^{\circ} \mathrm{PO}$ e apresenta funcionamento adequado do enxerto até a presente data (três meses follow-up).

O aspecto tomográfico de controle pós-operatório está demonstrado na figura 4.

O THV envolve uma cirurgia em um ser humano vivo e saudável, e essa questão é uma controvérsia ética há tempos, especialmente em países em que os doadores cadáveres são razoavelmente disponíveis ${ }^{11}$.

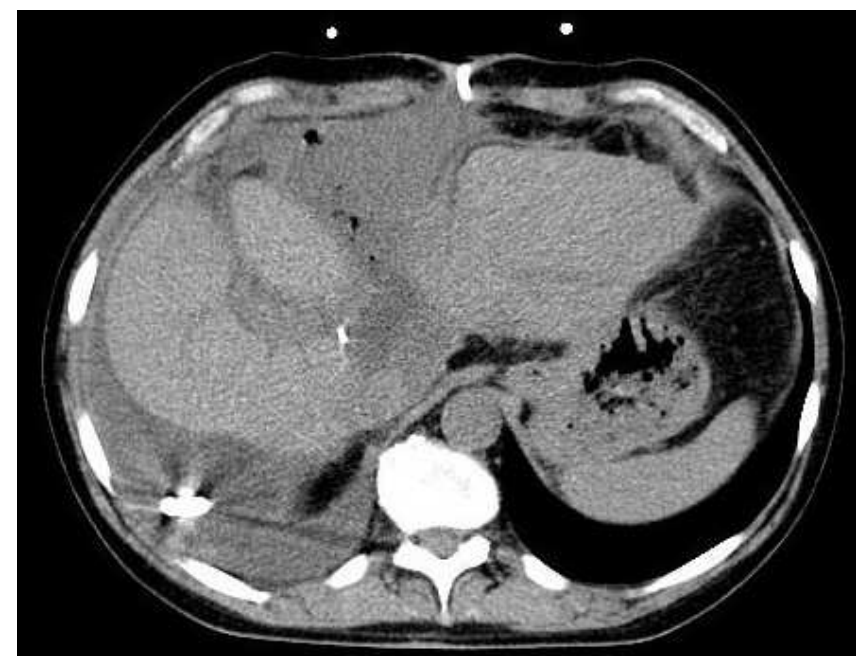

Figura 4 - Corte axial demonstrando os dois aloenxertos com 90 dias de pós-transplante.

Indubitavelmente o THV salva vidas, mas a um custo potencialmente muito alto ${ }^{8}$. Por esse motivo ainda é razão de debate se o THV é uma revolução ou uma "era negra" na história do transplante hepático ${ }^{12}$.

A demanda de recursos e a complexidade técnica do procedimento descrito é muito maior que os outros tipos de enxerto, porém é capaz de expandir a aplicabilidade do THV.

\section{Agradecimentos}

Os autores agradecem a imensa gama de profissionais envolvidos no pré, intra e pós-operatório que ajudaram decisivamente na realização do procedimento.

\section{A B S T R A C T}

Living donor liver transplantation expanded the therapeutic possibilities for liver failure patients. The necessary correct match between the liver mass donated and received sometimes limits its use. A case that was used two left liver grafts from adult living donors is reported.

Key words: Patients. Hepatic insufficiency. Transplants. Living donors. Liver transplantation.

\section{REFERENCIAS}

1. Raia S, Nery JR, Mies S. Liver transplantation from live donors. Lancet. 1989;2(8661):497.

2. Broelsch CE, Whitington PF, Emond JC, Heffron TG, Thistlethwaite $J R$, Stevens $L$, et al. Liver transplantation in children from living related donors. Surgical techniques and results. Ann Surg. 1991;214(4):428-37; discussion 437-9.

3. Otte JB. History of pediatric liver transplantation. Where are we coming from? Where do we stand? Pediatr Transplant. 2002;6(5):378-87.

4. Fan ST, Lo CM, Liu CL. Transplantation of the right hepatic lobe. N Engl J Med. 2002;347(8):615-8; author reply 615-8.
5. Schiano TD, Kim-Schluger L, Gondolesi G, Miller CM. Adult living donor liver transplantation: the hepatologist's perspective. Hepatology. 2001;33(1):3-9.

6. Said A, Williams J, Holden J, Remington P, Gangnon R, Musat A, et al. Model for end stage liver disease score predicts mortality across a broad spectrum of liver disease. J Hepatol. 2004;40(6):897-903.

7. Kim WR, Biggins SW, Kremers WK, Wiesner RH, Kamath PS, Benson $J T$, et al. Hyponatremia and mortality among patients on the livertransplant waiting list. N Engl J Med. 2008;359(10):1018-26.

8. Barr ML, Belghiti J, Villamil FG, Pomfret EA, Sutherland DS, Gruessner RW, et al. A report of the Vancouver Forum on the care of the live organ donor: lung, liver, pancreas, and intestine data and medical guidelines. Transplantation. 2006;81(10):1373-85. 
9. Pruett $T L$, Tibell A, Alabdulkareem A, Bhandari M, Cronin DC, Dew MA, et al. The ethics statement of the Vancouver Forum on the live lung, liver, pancreas, and intestine donor. Transplantation. 2006;81(10):1386-7.

10. Lee SG, Hwang S, Park KM, Kim KH, Ahn CS, Lee YJ, et al. Seventeen adult-to-adult living donor liver transplantations using dual grafts. Transplant Proc. 2001;33(7-8):3461-3.

11. Surman OS. The ethics of partial-liver donation. N Engl J Med 2002;346(14):1038

12. Ringe B, Strong RW. The dilemma of living liver donor death: to report or not to report? Transplantation. 2008;85(6):790-3.
Recebido em 03/06/2011

Aceito para publicação em 09/09/2011

Conflito de interesse: nenhum

Fonte de financiamento: nenhuma

\section{Como citar este artigo:}

Nicoluzzi JEL, Silveira F, Silveira FP, Macri MM, Monteiro M, Woitovicz, Stalchimidt F. Primeiro transplante duplo de fígado esquerdo intervivos adultos do Brasil. Rev Col Bras Cir. [periódico na Internet] 2012; 39(3).

Disponível em URL: http://www.scielo.br/rcbc

Endereço para correspondência:

João Eduardo Leal Nicoluzzi

E-mail: jenicoluzz@yahoo.com 